\title{
The Effectiveness of Hard Martial Arts in People over Forty: An Attempted Systematic Review
}

\section{Gaby Pons van Dijk ${ }^{1}{ }^{*}$, Pieter Leffers ${ }^{2}$ and Jan Lodder ${ }^{1}$}

1 Department of Neurology, University Hospital Maastricht and School for Mental Health and Neuroscience (MeHNS), 6202 AZ Maastricht, The Netherlands; E-Mail: j.lodder@mumc.nl

2 Department of Epidemiology and School for Public Health and Primary Care (CAPHRI), Faculty of Health, Medicine and Life Sciences, Maastricht University Medical Centre, 6229 ER Maastricht, The Netherlands; E-Mail: p.leffers@ maastrichtuniversity.nl

* Author to whom correspondence should be addressed; E-Mail: g.ponsvandijk@ mumc.nl; Tel.: +31-614-481-365; Fax: +31-433-877-055.

Received: 7 January 2014; in revised form: 3 April 2014 / Accepted: 22 April 2014 / Published: 30 April 2014

\begin{abstract}
The objective was to assess the effect of hard martial arts on the physical fitness components such as balance, flexibility, gait, strength, cardiorespiratory function and several mental functions in people over forty. A computerized literature search was carried out. Studies were selected when they had an experimental design, the age of the study population was $>40$, one of the interventions was a hard martial art, and when at least balance and cardiorespiratory functions were used as an outcome measure. We included four studies, with, in total, 112 participants, aged between 51 and 93 years. The intervention consisted of Taekwondo or Karate. Total training duration varied from 17 to 234 h. All four studies reported beneficial effects, such as improvement in balance, in reaction tests, and in duration of single leg stance. We conclude that because of serious methodological shortcomings in all four studies, currently there is suggestive, but insufficient evidence, that hard martial arts practice improves physical fitness functions in healthy people over 40 . However, considering the importance of such effects, and the low costs of the intervention, the potential of beneficial health effects of age-adapted, hard martial arts training, in people over 40, warrants further study.
\end{abstract}

Keywords: hard martial arts; Tae Kwon Do; senior citizens 


\section{Introduction}

The American College of Sport Medicine (ACSM) estimated that about $60 \%$ of Americans lack sufficient daily exercise, while about $25 \%$ has almost none [1]. In the Netherlands, about $25 \%$ of people lack sufficient daily physical activity, and about 10\% do not exercise at all [2,3] A low level of physical activity relates to an increased risk of cardiovascular disease, diabetes mellitus, osteoporosis, and has a negative effect on mood, cognitive functions and overall wellbeing. With increasing age these negative consequences lead to deterioration of mobility, jeopardizing self-maintenance and increase the chance of dependency on others [4-6]. Especially dynamic locomotor components deteriorate with age: steps become shorter, walking pace decreases, the time that both feet touch the ground increases during walking straight, but also in curves and while turning [6,7]. A decreased quality of the dynamic locomotor components also increases the risk of falling [8].

Exercise programs, including those based on martial arts, lower the chance of a number of negative consequences of aging [9]. Physical activity and sports which are mainly focused on the training of the proprioceptive system (balance sports like Tai Chi and Yoga) are effective in improving balance and in reducing the prevalence of falls in the elderly [7]. Such sports are clearly better to improve balance function than sports that aim to improve cardiovascular function (bioenergetic sports, such as running) [10].

Martial arts are often considered as either "soft", such as Tai Chi and Yoga, or "hard", such as Tae Kwon Do, Kung Fu, and Karate. Generally, hard martial arts focus on powerful execution of a limited number of movement techniques (those which most quickly and successfully take the opponent out), whereas soft martial arts primarily value the quality of execution of a much wider variety of movements; without losing sight of the fact that these movements relate to defense and attack patterns [11]. However, some martial arts, such as Tae Kwon Do, contain both elements. The element which makes hard martial techniques effective is the power to hit a target, which, apart from a certain degree of technique, requires both muscle strength and speed of execution. As most movements in the hard martial arts have a more dynamic nature than those in the soft martial arts, components of hard martial arts training may be expected to be especially beneficial on dynamic locomotor components [12].

A number of studies and reviews examined the effects of soft martial arts, especially Tai Chi, on some physical fitness components such as balance, but also on the risk of fall accidents in the elderly [6,13]

We hypothesize that hard martial art practice is more beneficial with regards to physical and mental functions because it combines the elements of soft martial arts with those of bioenergetics sports. Therefore, hard martial art practice could not only improve cardio-respiratory functions as in the bio-energetic sports, but also balance maintenance as in the soft martial arts. As the hard martial arts not only contain complex movement patterns as does, e.g., Tai Chi, they require a much more dynamic performance of these complexes, by which the physical fitness component "motor coordination" may especially benefit. A point of special interest, however, is balancing potential benefits against potential injuries, the occurrence of which may depend on the complexity and intensity of movement practice.

A review of 23 studies on effects on some physical functions of taekwondo training suggested benefits on aerobic capacity, body composition and flexibility. However, that review was descriptive and considered no age specification [13]. In this paper we sought to study the evidence whether hard martial art practice improves certain physical fitness components in people over 40 . We set the age 
limit at 40 for several reasons: above this age the sport practice has lost the aim of competitive gain, whereas it is almost exclusively practiced for fun and physical and mental benefit, which were the parameters for our review. As training practice intensity in this age group is generally lower than in youngsters and young adults, not only a lower risk of training injuries may be expected, but any effect on our parameters of interest may substantially vary between these age groups. Furthermore, there is a psychological reason when 40 years of age may be regarded as being half-way one's expected total life span of 80. If shown to be effective, such practice could then be recommended as an effective, safe and cost-effective method to improve certain health-related physical functions for people in this age category. With this aim we performed a systematic literature review of hard martial art intervention studies.

\section{Methods}

\subsection{Search Strategy}

We conducted a broad computerized literature search, over a period without a fixed date of onset up to May 2013, of Pubmed, Psychlit, Cochrane Database and Google search. Search terms were (a) hard martial arts; (b) participants older than 40 years; (c) measurements: balance, cardiorespiratory functions, mental functions (d) there was no time-limit and (e) written in English, Spanish, French, German or Dutch. This was specified with the following key words: martial arts, hard martial arts, Tae Kwon Do, Taekwondo, Karate, Hapkido, Kung Fu, older adults, aged, elderly and senior. We aimed primarily at (randomized) controlled trials, but also included other type prospective intervention studies.

The titles and abstracts of identified published articles were reviewed in order to determine their potential relevance tour aim. Also, reference lists of approved articles were screened for potentially relevant articles, which were reviewed in the same manner. In order to make a final selection of the studies for the review, one reviewer (GPD) applied all search criteria to the full text of the articles that had passed the first screening for eligibility.

\subsection{Risk of Bias Assessment}

A dedicated quality of methodology checklist was drawn up, based on of the published Delphi list, and with reference to the topic of the review [14]. The checklist was pretested using a non-randomized controlled study that studied the effects of Tai Chi on balance and selected motor functions of the elderly [15]. Only, minor changes had to be made for the final version (Table A1).

Two reviewers (GPD, PL) independently performed the methodological scoring of the selected studies. Their scores were compared and discrepancies were resolved through discussion between the reviewers. A third reviewer (JL) was to be consulted when differences could not easily be resolved.

\subsection{Data Extraction}

A study description form was developed based on standardized abstracting forms (Table A2). Data on all reported outcomes were extracted and assessed. 


\subsection{Analysis}

The methodological scoring list consisted of 18 items (see Table A1) with a positive, a partial and a negative answer option, they were scored as 2, 1 or 0 points respectively. If bias was considered unlikely, the item was scored positive. In case information was incomplete to allow good judgment, the item was scored as "partial", and without relevant information, "negative". The article was considered as poor with a score under 50\%, reasonable with a score 50\%-75\%, and good above $75 \%$. Heterogeneity between studies did not allow statistical pooling of study results.

\section{Results}

\subsection{Search Strategy}

Our search resulted in 13 references of potential studies. Based on title and abstract, nine references were selected and the full text review excluded three more, as the intervention in fact complied rather with soft martial arts. One article was conducted by our own research group and was excluded because of possible bias in assessing quality [16]. One study did not meet selection criteria, because it was a retrospective trial [17].

Eventually, four papers were included in this review [9,18-20]. See Figure 1.

Figure 1. Results of search.

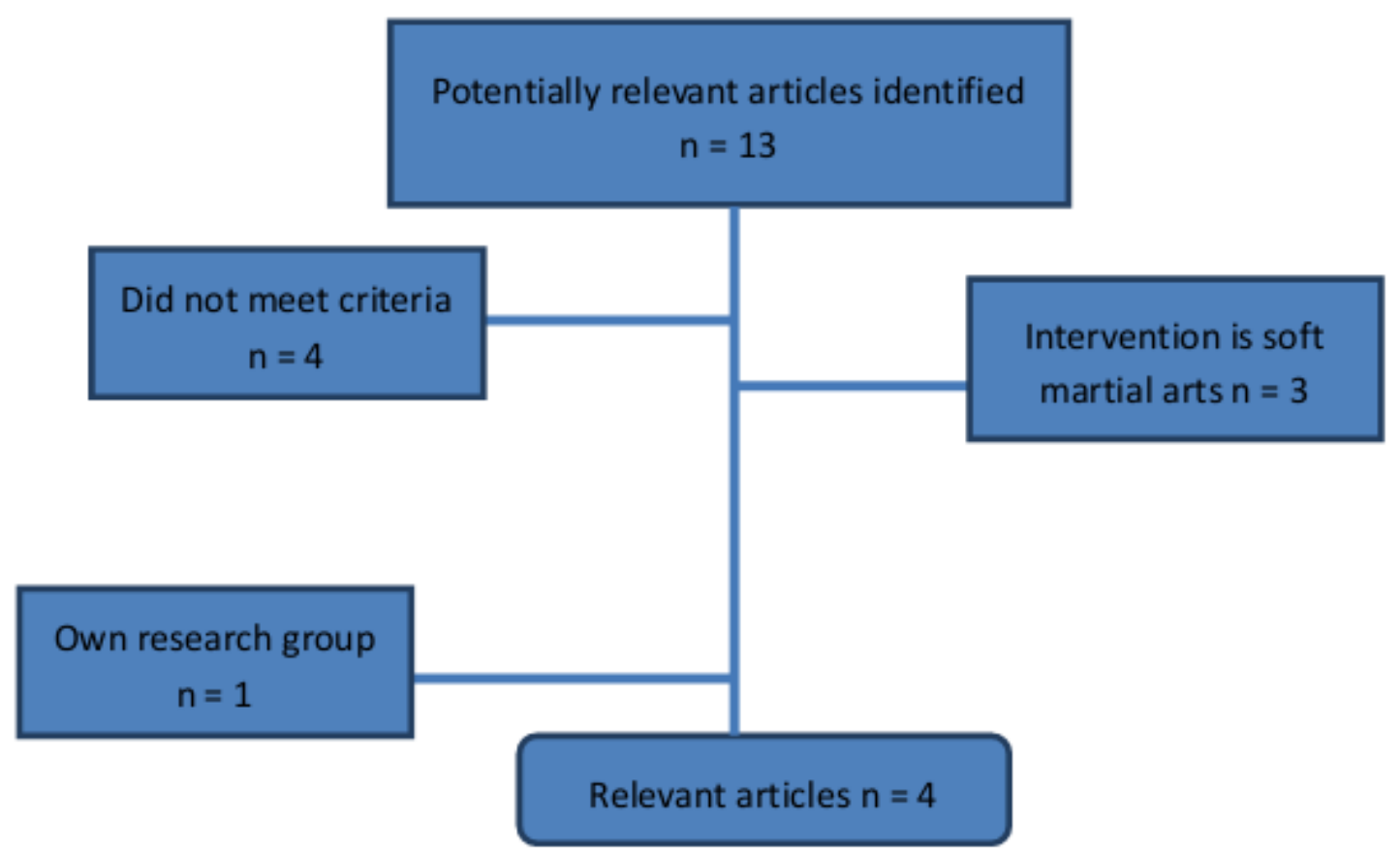

\subsection{Risk of Bias Assessment}

The four selected papers were two controlled trials, and two single arm intervention studies (Table 1). The little disagreement between reviewers occurred because of reading errors and differences in interpretation of the methodological criteria list. These differences could be easily resolved, and the third reviewer was not called upon. The results of the methodological assessment are presented in Table 2. 
Table 1. Characteristics of included studies.

\begin{tabular}{|c|c|c|c|c|c|}
\hline $\begin{array}{l}\text { Author } \\
\text { Year } \\
\text { Country }\end{array}$ & Design & Participants & Intervention & Reported Outcomes & Notes \\
\hline $\begin{array}{l}\text { Brudnak } \text { et al. } \\
2001 \text { [19] } \\
\text { Wisconsin, USA }\end{array}$ & SAI & $\begin{array}{l}\text { IG: } \text { Community-dwelling volunteers } \\
\quad \mathrm{N}=12: \delta / 9 \text { not mentioned } \\
\quad \text { Mean age: not mentioned (range: } 63-81 \text { ) } \\
\text { RG: - } \\
\text { Drop-out: } 50 \% \text {, after first class }\end{array}$ & $\begin{array}{ll}\text { IG: } & \text { Taekwondo } \\
& 17 \text { weeks } \\
& \text { once per week, } 1 \mathrm{~h} \\
& \text { total } 1020 \mathrm{~min} \\
\text { RG: } & -\end{array}$ & $\begin{array}{l}\text { Single leg stance: }(\mathrm{s}) \\
\text { Sit-and-reach }(\mathrm{cm}) \\
\text { Pushups (number in } 30 \mathrm{~s})\end{array}$ & $\begin{array}{l}\text { Participants } \\
\text { measured each } \\
\text { other in pairs }\end{array}$ \\
\hline $\begin{array}{l}\text { Cromwell et al. } \\
2007 \text { [9] } \\
\text { Texas, USA }\end{array}$ & CT & 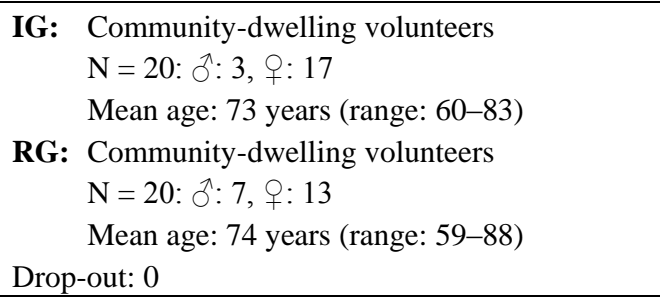 & $\begin{array}{l}\text { IG: } \\
\text { Taekwondo } \\
11 \text { weeks, } \\
\text { twice per week, } 1 \mathrm{~h} \\
\text { total } 1320 \text { min } \\
\text { RG: } \\
\text { normal daily physical activity }\end{array}$ & $\begin{array}{l}\text { Single leg stance }(\mathrm{s}) \\
\text { Multidirectional reach test }(\mathrm{cm}) \\
\text { Sit-and-reach }(\mathrm{cm}) \\
\text { Timed up-and-go }(\mathrm{s}) \\
\text { Cadence }(\text { steps/s) } \\
\text { Gait stability ratio }(\mathrm{steps} / \mathrm{s}) \\
\text { Walking velocity }(\mathrm{m} / \mathrm{s}) \\
\end{array}$ & \\
\hline $\begin{array}{l}\text { Chateau et al. } \\
2010 \text { [19] } \\
\text { Canada }\end{array}$ & SAI & $\begin{array}{l}\text { IG: Working } 50 \text { years old volunteers } \\
\quad \mathrm{N}=15: \overbrace{}^{\wedge} 15, q 0 \\
\quad \text { Median age: } 57 \text { years (range: } 51-58 \text { ) } \\
\text { RG: - } \\
\text { Drop-out: } 7\end{array}$ & $\begin{array}{l}\text { IG: Karate } \\
12 \text { months } \\
3 \text { times per week. } 1.5 \mathrm{~h} \\
\text { total: } 14040 \text { min } \\
\text { RG: - }\end{array}$ & $\begin{array}{l}\text { MOS } 36 \text { item Short Form Health Survey } \\
\text { Beck Depression Inventory } \\
\text { Reaction time (s) } \\
\text { Pronation and supination (s and } \mathrm{Hz}) \\
\text { Finger tapping (s and } \mathrm{Hz}) \\
\text { Sway path }(\mathrm{mm}) \\
\text { Sway area }\left(\mathrm{mm}^{2}\right) \\
\text { Sway velocity }(\mathrm{mm} / \mathrm{s}) \\
\text { Effort by ergometric bycicle (units not mentioned) }\end{array}$ & \\
\hline $\begin{array}{l}\text { Jansen } \text { et al. } \\
2012[20] \\
\text { Germany }\end{array}$ & CT & 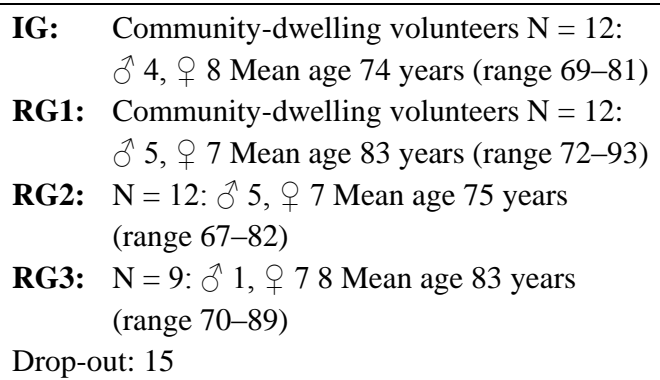 & $\begin{array}{ll}\text { IG: } & \text { Karate-Do } 3-6 \text { months } 20 \text { training } \\
& \text { sessions, } 1 \mathrm{~h} \text { total } 1200 \text { min } \\
\text { RG1: } & \begin{array}{l}\text { Physical exercise training } 20 \\
\text { training sessions, } 1 \mathrm{~h} \text { total } 1200 \mathrm{~min}\end{array} \\
\text { RG2: } & \begin{array}{l}\text { Cognitive training } 20 \text { training } \\
\text { sessions, } 1 \mathrm{~h} \text { total } 1200 \text { min }\end{array} \\
\text { RG3: } & \text { normal daily physical activity }\end{array}$ & $\begin{array}{l}\text { Number-connection test (min) } \\
\text { Number-symbol test (number of correct symbols) } \\
\text { Digit-span test (number of span) } \\
\text { Figure test (units not mentioned) } \\
\text { Block-tapping test (number of blocks) } \\
\text { Depression scale (score) }\end{array}$ & \\
\hline
\end{tabular}

$\mathrm{CT}=$ controlled trial; $\mathrm{SAI}=$ single arm intervention study; $\mathrm{IG}=$ index group; $\mathrm{RG}=$ reference group. 
Table 2. Methodology assessment.

\begin{tabular}{|c|c|c|c|c|c|c|c|c|c|}
\hline & & \multicolumn{2}{|c|}{ Brudnak et al. [18] } & \multicolumn{2}{|c|}{ Cromwell et al. [9] } & \multicolumn{2}{|c|}{ Chateau et al. [19] } & \multicolumn{2}{|c|}{ Jansen et al. [20] } \\
\hline & & Rating & Points & Rating & Points & Rating & Points & Rating & Points \\
\hline 1 & Randomization & No & $(0)$ & No & $(0)$ & No & $(0)$ & No & $(0)$ \\
\hline 2 & Intention to treat analysis & No & $(0)$ & No & $(0)$ & Partly & (1) & Partly & (1) \\
\hline 3 & Blinding assessors & No & $(0)$ & Inadequate & (1) & No & $(0)$ & No & $(0)$ \\
\hline 4 & Blinding participants & No & $(0)$ & No & $(0)$ & No & $(0)$ & No & $(0)$ \\
\hline 5 & Blinding providers & No & $(0)$ & No & $(0)$ & No & $(0)$ & No & $(0)$ \\
\hline 6 & Baseline characteristics & No RG & $(0)$ & No & $(0)$ & No RG & $(0)$ & No, age difference & $(0)$ \\
\hline 7 & Care programs identical & No & $(0)$ & No & $(0)$ & No & $(0)$ & Partly & (1) \\
\hline 8 & Inclusion criteria & Inadequate & (1) & Inadequate & (1) & Clear & (2) & No & $(0)$ \\
\hline 9 & Exclusion criteria & Inadequate & (1) & No & $(0)$ & Clear & (2) & No & $(0)$ \\
\hline 10 & Interventions & Not clear & $(0)$ & Clear & (2) & Clear & (2) & Not clear & $(0)$ \\
\hline 11 & Outcome measures clear & Clear & (2) & Clear & (2) & Inadequate & (1) & Inadequate & (1) \\
\hline 12 & Outcomes appropriately measured & Appropriate & (2) & No & $(0)$ & Appropriate & (2) & Inadequate & (1) \\
\hline 13 & Outcomes useful in daily activities & Adequate & (1) & Adequate & (1) & Adequate & (1) & Adequate & (1) \\
\hline 14 & Surveillance and duration & Inadequate & (1) & Good & (2) & Good & (2) & Inadequate & (1) \\
\hline 15 & Primary outcome defined & Inadequate & (1) & No & $(0)$ & No & $(0)$ & No & $(0)$ \\
\hline 16 & Compliance & Not clear & $(0)$ & Inadequate & (1) & Inadequate & (1) & Clear & (2) \\
\hline 17 & Adverse effects & Not described & $(0)$ & Not described & $(0)$ & Not described & $(0)$ & Not described & $(0)$ \\
\hline \multirow[t]{2}{*}{18} & Replicable & Partly & (1) & Partly & (1) & Yes & (2) & Partly & (1) \\
\hline & Quality Score & & $28 \%(10 / 36)$ & & $\mathbf{3 1 \%}(11 / 36)$ & & $44 \%(16 / 36)$ & & $\mathbf{2 5 \%}(9 / 36)$ \\
\hline
\end{tabular}




\subsection{Study Characteristics}

The study characteristics are presented in Table 1. Four studies with a total of 112 participants were included in this review, which came from two studies on Tae Kwon Do, and two studies on Karate.

Brudnak et al. tested one group of community-dwelling volunteers who followed Tae Kwon Do lessons for $1 \mathrm{~h}$ once a week, during 17 weeks. They functioned as their own reference group by measuring before and after the intervention period. The outcome variables were change of trunk flexibility, number of pushups and duration of single leg stance, and were measured before and following the training period [18].

Cromwell et al. divided the study population of community-dwelling volunteers, an index and a reference group, non-randomized. The division was based upon the choice of the volunteers. The index group followed a Taekwondo $1 \mathrm{~h}$ lessons twice a week, for 11 weeks. The Tae Kwon Do classes followed a standardized, clearly described curriculum. The non-exercising referents maintained their current lifestyle.

The outcome measures consisted of single leg stance, multidirectional reach test, timed up-and-go, walking velocity, cadence, gait stability ratio, sit-and-reach. They were measured before participation and after 11 weeks of Taekwondo lessons [9].

Chateau-Degat et al. tested 15 healthy 50-year-old males, who attended adapted karate training, which was clearly described, for at least three weekly sessions of $90 \mathrm{~min}$ each for 12 months. They functioned as their own reference group and were measured at least one week before training, 6 months and 12 months after participation [19]. The outcome measures consisted of the MOS 36-item Short Form Health Survey [21], the Beck Depression Inventory, reaction time, pronation and supination, finger tapping, sway path, area and sway velocity, and effort [19].

Jansen et al. considered four groups of elderly people between 67 and 93 years of age: a physical exercise group $(\mathrm{N}=12)$, a cognitive training group $(\mathrm{N}=12)$, one on Shokotan-Karate training $(\mathrm{N}=12)$, and a reference group $(\mathrm{N}=9)$. This division mainly came about by the volunteers' preference; inhabitants of different nursing homes wanted to stay together, as did (married) couples. In each of the 4 groups 20 training sessions were provided in a period of 3-6 months. The outcome measures were: cognitive speed, measured by the number-connection test and the number-symbol test; memory performance, measured by the digit-span-test, the figure test and the block-tapping test; and the Centre of Epidemiological Studies Depressions scale, which measures different stages of depressive symptoms. They were measured prior to training, whereas post-testing was done immediately after the last training session [20].

\subsection{Methodological Characteristics}

None of the studies had a randomized design. All the studies were performed after informed consent was given. See Table 2 for further details. An important confounder for outcome measures is compliance, which in Cromwell et al. it is not mentioned [9], whereas in Brudnak et al. there was a drop-out rate of more than 50\% after the first class [18]. Chateau-Degat et al. had a drop-out of 7 of 15 participants, whereas the attendance rate of the classes was not mentioned [19]. Jansen et al. 
mentioned the drop-outs before study start. The reference group in that study had fewer training sessions than the other groups [20].

Brudnak et al. measured one group of volunteers which functioned as their own reference group. There was no blinding since there was only one group and participants measured each other. In- and exclusion criteria were not well described; the authors did not explain why from the 27 recruited participants only 12 could continue with the study. Furthermore they describe an initial drop-out rate of $50 \%$, but it remains unclear how many participants did complete the intended number of the Tae Kwon Do classes. In effect on this indistinct description the mean age is uncertain, the participant's gender was not mentioned. The measurements conducted are described, and reproducible, however the quality of the measurements is doubtful since the participants measured each other. The Taekwondo classes are barely described, and it is unclear designed. Compliance and adverse effects were not described. The methodological scoring list is added to the addendum 1 and summarized in Table 2, the study scores an overall quality score of 10 out of 36 [18].

Cromwell et al. formed the groups based on patient preferences, the baseline characteristics were not entirely similar, but did not differ much. A chi-square test was performed to confirm similarity of health status between the Taekwondo and reference groups. The observers who measured the groups were blinded, but clearly the participants were not. In- and exclusion criteria were not mentioned in detail. No sample size calculation was performed prior to the study. The pre- and post-test measurements were clearly described, could easily be repeated and were applicable in daily activities. The intervention (Taekwondo) was clearly defined. Possible drop-outs were not mentioned. The measures were analyzed using an ANOVA for repeated measures. Participation compliance was well described and accounted for in analysis. Adverse effects were not reported. Therefore, the overall quality score is low and is 11 out of 36 (Table 2) [9].

The study of Chateau-Degat et al. is a clinical trial which recruited 22 healthy 50 -year-old male volunteers, who attended adapted karate training, so there were no women enrolled. The training content was well described and adapted to the participants' ability. Blinding was not possible since there was no reference group. It is unclear who conducted the measurements and whether these were conducted by the same assessors at baseline, 6 months and 12 months. The in- and exclusions were clearly described. There was a post hoc power sample size calculation; the power was $86.1 \%$, and considered adequate. The measurements were well described, but the outcome data were not described completely and remain, therefore, partly unclear. Furthermore, not all the measurements, particularly those at 6 months, were mentioned, but were only illustrated in a diagram. The drop-outs were well described. The analysis was made by conventional $t$-test, with Fisher's exact tests comparing proportions or by the Mann-Whitney U-test. Compliance and adverse effects are not mentioned. There is an intermediate overall quality score of 16out of 36 (Table 2) [19].

The study by Jansen et al. was a controlled intervention study. In total 45 older adults, ranging from 69 to 93 years of age, were enrolled. Inclusion and exclusion criteria were barely mentioned and not clear. A post hoc Bonferroni correction showed that the participants of the physical exercise and control group were significantly older than the participants in the other two groups. The intervention of the several groups was not described clearly. In particular, the content and intensity Karate training were vague. Although this was done "according to the German-Karate-Federation", how these were adapted to age was not described. Furthermore, outcome measurements were unclear and not rated 
blindly. As analysis they performed a univariate analysis of variance, and although some of the interactions were "statistically significant", this does not allow concluding that the intervention was causally related to the dependent variables. This all sums up to an overall quality score of 9 out of 36 (Table 2) [20].

\subsection{Outcome Measurements}

All the outcome measurements of the reviewed studies are listed in Table 3a-d.

\subsection{Analysis}

Our results show that all four included studies were of poor quality (score below 50\%).

Table 3. Results.

(a). Results of Brudnak et al. [18].

\begin{tabular}{cccc}
\hline & & Index & \\
& & Group & \\
\hline Article & Measurement & Pre & Post \\
& & mean & mean \\
\hline Brudnak & Sit-and-reach (cm) & Increase & $>8.9$ \\
{$[18]$} & Pushups (number per 30 s) & Increase & 1.8 \\
& Single leg stance (s): Right & Increase & $>16$ \\
& Left & Increase & 16 \\
\hline
\end{tabular}

Pre $=$ Before training; Post $=$ After training. 
(b). Results of Cromwell et al. [9].

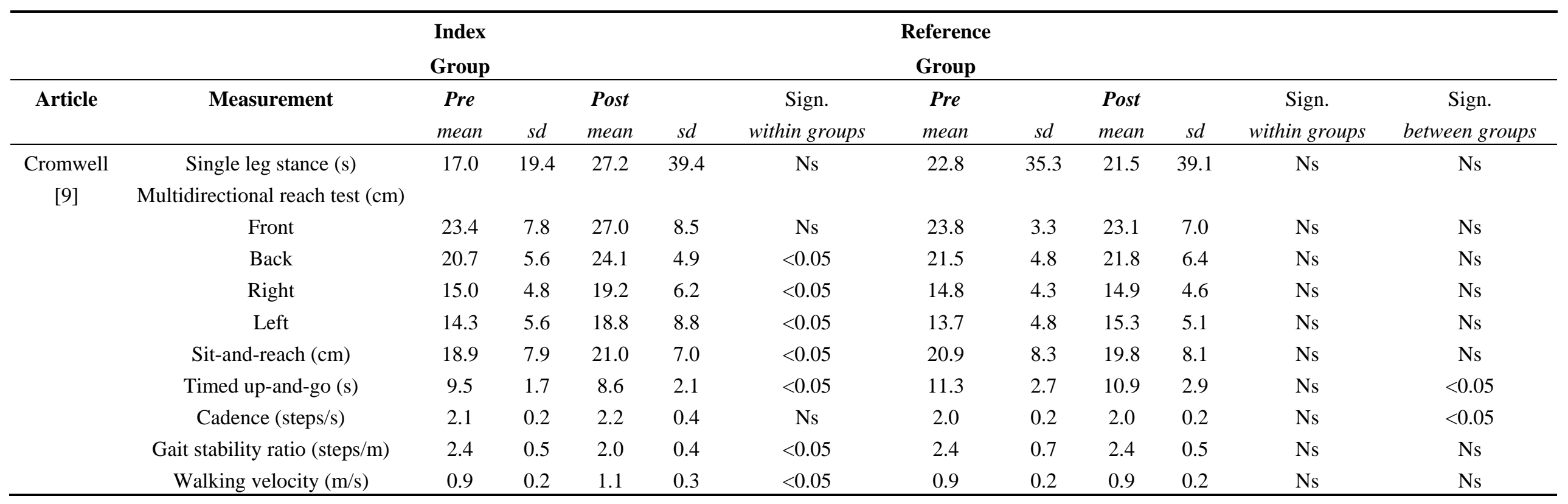

Pre $=$ Before training; Post $=$ After training; $s d=$ Standard deviation; Sign $=$ Significance $(p<0.05)$. 
(c). Results of Chateau et al. [19].

\begin{tabular}{|c|c|c|c|c|c|c|c|c|c|}
\hline \multirow[t]{2}{*}{ Article } & \multirow[t]{2}{*}{ Measurement } & \multirow[t]{2}{*}{ Pre } & \multirow[b]{2}{*}{ sd } & \multirow[t]{2}{*}{6 months } & \multicolumn{3}{|c|}{12 months } & \multirow{2}{*}{$\begin{array}{c}\text { Sign. pre } v s . \\
6 \text { months } \\
\end{array}$} & \multirow{2}{*}{$\begin{array}{c}\text { Sign. pre } v s . \\
12 \text { months }\end{array}$} \\
\hline & & & & & sd & & sd & & \\
\hline Chateau & Physical score & 29.8 & 1.1 & $\mathrm{Nm}$ & $\mathrm{Nm}$ & 34.7 & 1.1 & $\mathrm{Nm}$ & 0.01 \\
\hline \multirow[t]{26}{*}{ [19] } & Mental score & 50.9 & 1.3 & $\mathrm{Nm}$ & $\mathrm{Nm}$ & 50.2 & 1.3 & $\mathrm{Nm}$ & 0.67 \\
\hline & Physical functioning (score) & 81.9 & 1.9 & $\mathrm{Nm}$ & $\mathrm{Nm}$ & 88.0 & 1,9 & $\mathrm{Nm}$ & 0.02 \\
\hline & Physical status (score) & $\mathrm{Nm}$ & $\mathrm{Nm}$ & $\mathrm{Nm}$ & $\mathrm{Nm}$ & $\mathrm{Nm}$ & $\mathrm{Nm}$ & $\mathrm{Nm}$ & \\
\hline & Body pain (score) & 69.9 & 2.2 & $\mathrm{Nm}$ & $\mathrm{Nm}$ & 84.5 & 2.4 & $\mathrm{Nm}$ & 0.04 \\
\hline & General health (score) & 13.9 & 0.7 & $\mathrm{Nm}$ & $\mathrm{Nm}$ & 16.4 & 0.7 & $\mathrm{Nm}$ & 0.01 \\
\hline & Vitality (score) & 61.0 & 1.6 & $\mathrm{Nm}$ & $\mathrm{Nm}$ & 69.12 & 1.6 & $\mathrm{Nm}$ & $<0.01$ \\
\hline & Social functioning (score) & $\mathrm{Nm}$ & $\mathrm{Nm}$ & $\mathrm{Nm}$ & $\mathrm{Nm}$ & $\mathrm{Nm}$ & $\mathrm{Nm}$ & $\mathrm{Nm}$ & 0.77 \\
\hline & Emotional status (score) & $\mathrm{Nm}$ & $\mathrm{Nm}$ & $\mathrm{Nm}$ & $\mathrm{Nm}$ & $\mathrm{Nm}$ & $\mathrm{Nm}$ & $\mathrm{Nm}$ & 0.50 \\
\hline & Mental health (score) & $\mathrm{Nm}$ & $\mathrm{Nm}$ & $\mathrm{Nm}$ & $\mathrm{Nm}$ & $\mathrm{Nm}$ & $\mathrm{Nm}$ & $\mathrm{Nm}$ & 0.95 \\
\hline & Reaction time (s) Right & 0.23 & 0.01 & 0.23 & 0.01 & 0.23 & 0.01 & 0.71 & 0.86 \\
\hline & Left & 0.20 & 0.01 & 0.23 & 0.01 & 0.24 & 0.01 & 0.01 & 0.01 \\
\hline & Pronation and supination & & & & & & & & \\
\hline & Precision (s) Right & 0.01 & 0.02 & -0.02 & 0.02 & -0.26 & 0.02 & 0.04 & 0.11 \\
\hline & Left & -0.03 & 0.02 & -0.04 & 0.02 & -0.36 & 0.02 & 0.41 & 0.66 \\
\hline & Regularity Right & 0.06 & 0.01 & 0.06 & 0.01 & 0.06 & 0.01 & 0.37 & 0.96 \\
\hline & Left & 0.05 & 0.01 & 0.05 & 0.01 & 0.05 & 0.01 & 0.15 & 0.82 \\
\hline & Maximum (Hz) Right & 5.43 & 0.32 & 6.07 & 0.30 & 6.10 & 0.32 & $<0.01$ & 0.04 \\
\hline & Left & 5.07 & 0.24 & 5.85 & 0.23 & 5.88 & 0.26 & $<0.01$ & $<0.01$ \\
\hline & Finger tapping & & & & & & & & \\
\hline & Precision (s) Right & -0.09 & 0.01 & -0.06 & 0.01 & -0.06 & 0.01 & 0.01 & 0.10 \\
\hline & Left & -0.09 & 0.01 & -0.06 & 0.01 & -0.06 & 0.02 & 0.09 & 0.28 \\
\hline & Regularity Right & 0.09 & 0.01 & 0.06 & 0.01 & 0.06 & 0.01 & 0.03 & 0.08 \\
\hline & Left & 0.07 & 0.01 & 0.07 & 0.01 & 0.08 & 0.01 & 0.49 & 0.42 \\
\hline & Maximum Right & 6.72 & 0.27 & 6.35 & 0.27 & 6.23 & 0.30 & 0.27 & 0.24 \\
\hline & Left & 6.09 & 0.39 & 6.98 & 0.39 & 6.85 & 0.43 & 0.10 & 0.21 \\
\hline & Mean sway Eyes $(\mathrm{mm})$ open & 5.6 & 0.5 & 6.0 & 0.5 & 6.1 & 0.5 & 0.36 & 0.36 \\
\hline
\end{tabular}


(c). Cont.

\begin{tabular}{|c|c|c|c|c|c|c|c|c|c|}
\hline \multirow[t]{2}{*}{ Article } & \multirow[t]{2}{*}{ Measurement } & \multicolumn{2}{|l|}{ Pre } & \multirow[t]{2}{*}{6 months } & \multicolumn{3}{|c|}{12 months } & \multirow{2}{*}{$\begin{array}{c}\text { Sign. pre } v s . \\
6 \text { months }\end{array}$} & \multirow{2}{*}{$\begin{array}{c}\text { Sign. pre } v s . \\
12 \text { months }\end{array}$} \\
\hline & & & sd & & sd & & sd & & \\
\hline Chateau & Closed & 6.71 & 0.6 & 5.9 & 0.6 & 5.9 & 0.6 & 0.05 & 0.19 \\
\hline \multirow[t]{15}{*}{ [19] } & Transversal sway (mm) Open & 3.0 & 0.2 & 3.1 & 0.2 & 3.1 & 0.2 & 0.46 & 0.57 \\
\hline & Closed & 3.9 & 0.4 & 3.4 & 0.3 & 3.3 & 0.4 & 0.10 & 0.17 \\
\hline & Sagittal sway (mm) Open & 4.1 & 0.5 & 4.4 & 0.5 & 4.6 & 0.5 & 0.43 & 0.40 \\
\hline & Closed & 4.6 & 0.5 & 4.1 & 0.4 & 4.2 & 0.5 & 0.12 & 0.40 \\
\hline & Sway area $(\mathrm{mm} 2)$ Open & 316.6 & 40.0 & 315.2 & 38.6 & 321.3 & 0.8 & 0.96 & 0.80 \\
\hline & Closed & 507.9 & 87.5 & 404.9 & 84.1 & 399.2 & 89.3 & 0.09 & 0.22 \\
\hline & Sway velocity $(\mathrm{mm} / \mathrm{s})$ Open & 11.4 & 0.9 & 10.6 & 0.9 & 10.5 & 0.9 & 0.16 & 0.33 \\
\hline & Closed & 17.5 & 1.9 & 14.4 & 1.8 & 14.4 & 1.9 & 0.02 & 0.01 \\
\hline & Sway intensity $(\mathrm{mm})$ Open & 4.4 & 0.3 & 4.4 & 0.3 & 4.4 & 0.3 & 0.97 & 0.93 \\
\hline & Closed & 6.2 & 0.5 & 5.4 & 0.5 & 5.4 & 0.5 & 0.01 & 0.04 \\
\hline & Duration of effort (min) & 10.9 & 0.5 & $\mathrm{Nm}$ & $\mathrm{Nm}$ & 12.2 & 0.6 & $\mathrm{Nm}$ & 0.04 \\
\hline & Maximal power developed & 198.0 & 10.0 & 214.8 & 10.2 & & & 0.01 & 0.01 \\
\hline & Maximal heart rate (beats/min) & $\mathrm{Nm}$ & $\mathrm{Nm}$ & $\mathrm{Nm}$ & $\mathrm{Nm}$ & $\mathrm{Nm}$ & $\mathrm{Nm}$ & $\mathrm{Nm}$ & $\mathrm{Nm}$ \\
\hline & Individual effort profile & $\mathrm{Nm}$ & $\mathrm{Nm}$ & $\mathrm{Nm}$ & $\mathrm{Nm}$ & $\mathrm{Nm}$ & $\mathrm{Nm}$ & $\mathrm{Nm}$ & $\mathrm{Nm}$ \\
\hline & Beck depression score & 9.8 & 1.1 & 4.9 & 1.0 & 4.9 & 1.1 & 0.01 & $<0.01$ \\
\hline
\end{tabular}

Pre $=$ Before training; 6 months = After 6 months training; 12 months = After 12 months training; sd = Standard deviation Sign= Significance $(P<0.05)$; $\mathrm{Nm}=$ Not mentioned. 
(d). Results of Jansen et al. [20].

\begin{tabular}{|c|c|c|c|c|c|c|c|c|c|c|c|c|}
\hline Article & Measurement & $\begin{array}{c}\text { RG } \\
\text { Mean }\end{array}$ & SE & $\begin{array}{c}\text { EG } \\
\text { Mean } \\
\end{array}$ & SE & $\begin{array}{c}\text { CT } \\
\text { Mean } \\
\end{array}$ & SE & $\begin{array}{l}\text { Karate } \\
\text { Mean }\end{array}$ & SE & $\begin{array}{c}\text { Effect of } \\
\text { group }\end{array}$ & $\begin{array}{c}\text { Effect of } \\
\text { time of testing }\end{array}$ & Interaction \\
\hline Jansen & Cognitive speed & & & & & & & & & & & \\
\hline \multirow[t]{6}{*}[20]{} & Number-connection test (s) & 45.51 & 3.8 & 29.72 & 3.45 & 23.83 & 3.28 & 29.31 & 3.41 & $6.31 *$ & 0.01 & 0.125 \\
\hline & Memory performance & $\mathrm{Nm}$ & $\mathrm{Nm}$ & $\mathrm{Nm}$ & $\mathrm{Nm}$ & $\mathrm{Nm}$ & $\mathrm{Nm}$ & $\mathrm{Nm}$ & $\mathrm{Nm}$ & & & \\
\hline & Digit-span test (number) & $\mathrm{Nm}$ & $\mathrm{Nm}$ & $\mathrm{Nm}$ & $\mathrm{Nm}$ & $\mathrm{Nm}$ & $\mathrm{Nm}$ & $\mathrm{Nm}$ & $\mathrm{Nm}$ & 1.5 & 0.22 & 1.6 \\
\hline & Figure test (score) & $\mathrm{Nm}$ & $\mathrm{Nm}$ & $\mathrm{Nm}$ & $\mathrm{Nm}$ & $\mathrm{Nm}$ & $\mathrm{Nm}$ & $\mathrm{Nm}$ & $\mathrm{Nm}$ & 1.63 & 1.01 & 0.74 \\
\hline & & Pre & Post & Pre & Post & Pre & Post & Pre & Post & & & \\
\hline & Depression score & 11 & 12.5 & 13.5 & 13 & 10 & 18 & 13 & 8 & 0.81 & 0.84 & 4.12 \\
\hline
\end{tabular}

$\mathrm{RG}=$ Reference group; EG = Exercise group; $\mathrm{CT}=$ Cognitive training; sd = Standard deviation; SE = Standard error; Nm = Not mentioned; Pre =Before intervention; Post $=$ After intervention. 


\section{Discussion and Conclusions}

Our aim was to do a systematic review of the available literature. Although our methods complied with this aim, both quality and quantity of the material we analyzed did not allow us to explicitly fulfill our original goal.

The number of reviewed studies was limited, as was their methodological quality, which illustrates the lack of research in the area of health benefits of hard martial arts in people over 40 . We found four studies, which were all of a small size, whereas their intervention duration was rather short. Furthermore, there were large differences in study design, outcome measures, methodological quality, and character of training content. With only four studies found, one may consider a systemic review to be a bit premature. However, our review may make investigators well aware of the idea that further study is needed. The studies, nevertheless, suggest some benefit, and if proper studies could confirm beneficial effects of hard martial arts training, such training could eventually be recommended as a hopefully safe, pleasant and cheap way to maintain or even improve various physical fitness functions in people over 40 . Whether, or to what extent, benefits outweigh the risk of training injury cannot be inferred from the four studies, as neither injury frequency nor injury severity was reported. This is certainly an issue that should be included in any future studies. Preliminary data suggest that when training programming is adjusted to account for age-related requirements, training injuries are minor [22]. When looking at the proportion of ageing people in society who maintain a sedentary lifestyle, substantial gain in health on a societal level might be attained if this age group could be convinced to practice hard martial art forms. Such an approach could result in significant savings in healthcare costs at a minimal amount of investment. An important potential benefit may be the mitigation of age-related deterioration in mobility, which increases falls and jeopardizes self-maintenance, both of which are rather costly affairs for society, especially when the proportion of aged and very old people is on the increase $[4,6,13]$.

Subjective benefits from martial arts training is often reported, especially in (generally Asian) countries where the various arts originated. Without doubt we missed reports in the Asian languages, and we cannot exclude such a language bias in our survey. Originally we aimed to include Kung Fu as a hard martial art in our review, but the nine studies covered in a 2008 systematic review of health benefits of this art were all on younger age groups, whereas we were unable to find any later published study on an age group above 40 [23].

We excluded one study because it was a retrospective study and thus not an experimental design: Douris et al. investigated a group of martial arts practitioners and a reference group consisting of sedentary community members. The martial arts practitioners had participated in Soo Bahk Do training during three years or more, a minimum of twice a week for $1 \mathrm{~h}$ a day. All classes were led by a certified Soo Bahk Do instructor. The reference group did not engage in physical exercise other than normal daily activities. Single leg stance was significantly longer with $35 \mathrm{~s}$ more, the sit-and-reach test showed a difference of $11.8 \mathrm{~cm}$ in favor of the Soo Bahk Do group, with a $p$-value of 0.01 [17].

The Karate and Taekwondo studies incorporate straight line powerful blocking, kicking and punching techniques as a major exercise component. However, generally the rates of kicking techniques, often combined with turning and jumping movements, amount to about $75 \%$ of exercises in Taekwondo, but only $25 \%$ in Karate. Therefore, although these various styles are all listed as "hard" 
martial art, they differ quite substantially in technical content, and their effects on separate physical fitness components may also vary. Especially the practice of more dynamic movement patterns, such as practiced in Taekwondo, may stimulate balance function. The four studies listed in this paper also showed differences in training effects, but the numbers were too small for a reliable comparison.

From this review we may conclude that current evidence that hard martial arts practice improves physical fitness functions in healthy people over 40 is suggestive, but not convincing. Our analysis together with the consideration of the potential health and health cost benefit, leads us also to conclude that the subject warrants further study. New studies should be properly designed, report training programming, dose, and assessment, and also report on adverse events, whereas criteria for outcome assessment should clearly be described. Studies should have a set duration of the training intervention of probably at least one year, whereas they may focus not only on physical but also on cognitive aspects. Moreover, aspects such as safety, program feasibility, and long-term adherence should also be addressed. More reliable data are required before age-adapted hard martial art training in people over 40 can be recommended as a means to mitigate the age-related decline of various physical functions.

\section{Author Contributions}

G. Pons van Dijk conducted the search for the reviewed articles and together with P. Leffers they determined all the criteria and selected the articles. G. Pons van Dijk and P. Leffers both reviewed the articles. In case of any differences J. Lodder was consulted. G. Pons van Dijk wrote the paper and P. Leffers and J. Lodder suggested corrections.

\section{Appendixes}

Table A1. Quality rating (internal validity).

\begin{tabular}{|c|c|c|c|}
\hline & Item & Points & Rating \\
\hline & \multirow{3}{*}{$\begin{array}{l}\text { Was the assigned intervention adequately } \\
\text { concealed prior to allocation? }\end{array}$} & 2 & Method did not allow disclosure of assignment \\
\hline & & 1 & Small but possible chance of disclosure of assignment or unclear \\
\hline & & 0 & Quasi-randomized or open list/tables \\
\hline \multirow[t]{3}{*}{2.} & \multirow{3}{*}{$\begin{array}{l}\text { Were the outcomes of participants who } \\
\text { dropped out described and included in the } \\
\text { analysis (intention to treat)? }\end{array}$} & 2 & Drop outs well described and accounted for in analysis \\
\hline & & 1 & Drop outs described and analysis is not possible \\
\hline & & 0 & No mention, inadequate mention or obvious differences and no adjustment \\
\hline \multirow{3}{*}{3.} & \multirow{3}{*}{$\begin{array}{l}\text { Were the outcome assessors blinded to } \\
\text { intervention status? }\end{array}$} & 2 & Effective action taken to blind assessors \\
\hline & & 1 & Small or moderate chance of unblinding of assessors \\
\hline & & 0 & Not mentioned or not possible \\
\hline \multirow{3}{*}{4.} & \multirow{3}{*}{$\begin{array}{l}\text { Were the participants blind to assignment } \\
\text { status after allocation? }\end{array}$} & 2 & Effective action taken to blind participants \\
\hline & & 1 & Small or moderate chance of unblinding of participants \\
\hline & & 0 & Not possible or not mentioned, or possible but not done \\
\hline \multirow{3}{*}{5.} & \multirow{3}{*}{$\begin{array}{l}\text { Were the intervention providers blind to } \\
\text { assignment status? }\end{array}$} & 2 & Effective action taken to blind intervention providers \\
\hline & & 1 & Small or moderate chance of unblinding of intervention providers \\
\hline & & 0 & Not possible or not mentioned, or possible but not done \\
\hline \multirow{3}{*}{6.} & \multirow{3}{*}{$\begin{array}{l}\text { Were the intervention and control group } \\
\text { comparable at entry? }\end{array}$} & 2 & Good comparability of groups, or confounding adequately adjusted for in analysis \\
\hline & & 1 & Confounding small; mentioned but not adjusted for \\
\hline & & 0 & Large potential for confounding, or not discussed \\
\hline \multirow{3}{*}{7.} & \multirow{3}{*}{$\begin{array}{l}\text { Were care programs, other than the } \\
\text { intervention identical (co-intervention)? }\end{array}$} & 2 & Care programs clearly identical \\
\hline & & 1 & Clear but trivial differences \\
\hline & & 0 & Not mentioned or clear and important differences in care programs \\
\hline
\end{tabular}


Table A1. Cont.

\begin{tabular}{|c|c|c|c|}
\hline & Item & Points & Rating \\
\hline \multirow[t]{3}{*}{8.} & Were the inclusion criteria clearly & 2 & Clearly defined \\
\hline & defined, appropriate selection of study & 1 & Inadequately defined \\
\hline & participants, for the purpose of the study? & 0 & Not defined \\
\hline \multirow[t]{3}{*}{9.} & Were the exclusion criteria clearly & 2 & Clearly defined \\
\hline & defined, appropriate selection of study & 1 & Inadequately defined \\
\hline & participants, for the purpose of the study? & 0 & Not defined \\
\hline \multirow{3}{*}{10.} & \multirow{3}{*}{$\begin{array}{l}\text { Were the interventions clearly defined } \\
\text { and appropriately applied? }\end{array}$} & 2 & Clearly defined interventions are applied with a standardized protocol \\
\hline & & 1 & Clearly defined interventions are applied but the application protocol is not standardized \\
\hline & & 0 & Intervention and/or application protocol are poorly or not defined \\
\hline \multirow{3}{*}{11.} & \multirow{3}{*}{$\begin{array}{l}\text { Were the outcome measures used clearly } \\
\text { defined? }\end{array}$} & 2 & Clearly defined \\
\hline & & 1 & Inadequately defined \\
\hline & & 0 & Not defined \\
\hline \multirow{3}{*}{12.} & \multirow{3}{*}{$\begin{array}{l}\text { Were the outcome measures used } \\
\text { appropriately measured? }\end{array}$} & 2 & Appropriately measured \\
\hline & & 1 & Inadequately measured \\
\hline & & 0 & Not defined \\
\hline \multirow{3}{*}{13.} & \multirow{3}{*}{$\begin{array}{l}\text { Were test used in outcome assessment } \\
\text { useful in daily activities? }\end{array}$} & 2 & Optimal \\
\hline & & 1 & Adequate \\
\hline & & 0 & Not defined, not adequate \\
\hline \multirow{3}{*}{14.} & \multirow{3}{*}{$\begin{array}{l}\text { Was the surveillance active and of } \\
\text { appropriate duration? }\end{array}$} & 2 & Active surveillance and appropriate duration \\
\hline & & 1 & Active surveillance, but inadequate duration \\
\hline & & 0 & Surveillance not active or not defined \\
\hline \multirow[t]{3}{*}{15.} & \multirow{3}{*}{$\begin{array}{l}\text { Were point estimates and measures of } \\
\text { variability presented for the primary } \\
\text { outcome measures? }\end{array}$} & 2 & Yes \\
\hline & & 1 & Point estimates, but no measures of variability presented \\
\hline & & 0 & Vague descriptions \\
\hline \multirow{3}{*}{16.} & \multirow{3}{*}{$\begin{array}{l}\text { Was the compliance rate in each group } \\
\text { likely to cause bias? }\end{array}$} & 2 & Compliance well described and accounted for in analysis \\
\hline & & 1 & Compliance well described but differences between groups not accounted for in analysis \\
\hline & & 0 & Compliance unclear \\
\hline \multirow{3}{*}{17.} & \multirow{3}{*}{$\begin{array}{l}\text { Was there a description of adverse effects } \\
\text { of the intervention? }\end{array}$} & 2 & Well described \\
\hline & & 1 & Poorly described \\
\hline & & 0 & Not described \\
\hline \multirow{3}{*}{18.} & \multirow{3}{*}{$\begin{array}{l}\text { Is the intervention replicable and } \\
\text { feasible? }\end{array}$} & 2 & Yes \\
\hline & & 1 & Partly \\
\hline & & 0 & No \\
\hline
\end{tabular}

Table A2. Study description/characteristics inventory.

\begin{tabular}{lll}
\hline \multicolumn{1}{c}{ Category } & \\
\hline & Type of study design & RCT, Controlled Trial, uncontrolled Trial, cohort; cross-section \\
Method of group allocation & Random number table; computer random number generator; coin toss & Therapist and/or patient; sealed envelopes \\
Besign & Duration of follow-up period & sample size needed for adequate statistical power \\
\hline Power sample size calculation & \\
Setting & \\
& Country & \\
& Year of study & \\
\hline
\end{tabular}


Table A2. Cont.

\begin{tabular}{|c|c|c|}
\hline \multirow{7}{*}{ Planned interventions } & Description of experimental intervention & Type of martial arts; description of content of training sessions \\
\hline & Description of reference intervention & \\
\hline & Time per intervention session & \\
\hline & Frequency intervention sessions & \\
\hline & Duration of intervention period & \\
\hline & Total number of interventions & \\
\hline & Cumulative training time in study & \\
\hline \multirow{4}{*}{ Outcome definition } & All collected outcomes variables & Units of measurement, upper and lower limits of ordinal scales \\
\hline & Measurements & \\
\hline & Time points of collected data & \\
\hline & Adverse effects & \\
\hline \multirow{6}{*}{ Subjects per group } & Number of subjects & \\
\hline & Ethnicity & Proportions \\
\hline & Age & Mean and SD; median; range \\
\hline & Gender & Proportions \\
\hline & Socio-demographic characteristics & \\
\hline & Co-morbidity & \\
\hline \multirow{6}{*}{ Reported results per group } & Outcome measures & Proportions; means and SD; medians; ranges \\
\hline & Intention to treat analysis & \\
\hline & Cumulative training time & \\
\hline & Loss to follow-up & \\
\hline & Summary of all outcome measurements & \\
\hline & Adverse events & \\
\hline \multirow{4}{*}{ Data analysis } & Type of analysis & Intention to treat; per protocol analysis \\
\hline & Estimates of effect measures & $\mathrm{RR},(\mathrm{OR}), \mathrm{AR}, \mathrm{NNT}$, difference of means; CI's and/or p-values \\
\hline & Subgroup analysis & Differences of effect measures between subgroups \\
\hline & Drop outs & Drop out, lost to follow-up, missing data, crossover \\
\hline \multirow{4}{*}{ Limitations } & Internal validity & Research question free from bias, methodology \\
\hline & Confounding & Differences in baseline characteristics \\
\hline & Concerns about external validity & Appropriate research question, generalizability/applicability of findings \\
\hline & Main conclusions according to authors & \\
\hline \multirow{3}{*}{ Miscellaneous } & Source of funding & \\
\hline & Year of publication & \\
\hline & Miscellaneous comments from authors & \\
\hline
\end{tabular}

$\mathrm{RCT}=$ Randomized controlled trial; $\mathrm{SD}=$ Standard deviation; $\mathrm{RR}=$ Relative risk; $\mathrm{OR}=$ Odds ratio; NNT $=$ Number needed to treat CI $=$ Confidence interval.

\section{Conflicts of Interest}

The authors declare no conflict of interest. This article does not contain any studies with human or animal subjects performed by any of the authors. 


\section{References}

1. American College of Sports Medicine. Acms's Resource Manual for Guidelines for Exercise Testing and Prescription, 6th ed.; Lippincott Williams and Wilkins: Philadelphia, PA, USA, 2001; pp. 57-90.

2. Kroes, G.; de Greef, M. National initiatives for the promotion of physical activity for older persons in the Netherlands. J. Aging Phys. Act 2000, 8, 431-435.

3. Lobstein, T.; Rigby, N.; Leach, R. EU platform on diet, physical activity and health. Available online: http://ec.europa.eu/health/ph_determinants/life_style/nutrition/documents/iotf_en.pdf (accessed on 15 March 2005).

4. Cress, M.E; Buchner, D.M.; Questad, K.A.; Esselman, P.C.; de Lateur, B.J.; Schwartz, R.S.A. Exercise: Effects on physical functional performance in independent older adults. $J$ Gerontol. Med. Sci. 1995, 54A, 242-248.

5. Buchner, D.; Cress, M.E.; de Lateur, B.J.; Esselman, P.C.; Margherita, A.J.; Price, R.; Wagner, E.H. A comparison of the effects of three types of endurance training on balance and other fall risk factors in older adults. Aging Clin. Exp. Res. 1997, 9, 112-119.

6. Cameron, I.D.; Gillespie, L.D.; Robertson, M.C.; Murray, G.R.; Hill, K.D.; Cumming, R.G.; Kerse, N. Interventions for preventing falls in older people in care facilities and hospitals. Cochrane Database Syst. Rev. 2012, 12, doi:10.1002/14651858.CD005465.pub3.

7. Rubenstein, L.Z.; Josephson, K.R. The epidemiology of falls and syncope. Clin. Geriatr. Med. 2002, 18, 141-158.

8. Hausdorff, J.M.; Rios, D.A.; Edelber, H.K. Gait variability and fall risk in community-living older adults: A 1-year prospective study. Arch. Phys. Med. Rehabil. 2001, 82, 1050-1056.

9. Cromwell, R.L.; Meyers, P.M.; Meyers, P.E.; Newton, R.A. Taekwondo: An effective exercise for improving balance and walking ability in older adults. J. Gerontol.: Med. Sci. 2007, 62A, 641-646.

10. Gauchard, G.C.; Gangloff, P.; Jeandel, C.; Perrin, P.P. Influence of regular proprioceptive and bioenergetic physical activities on balance control in elderly women. J. Gerontol. A Biol. Sci. Med. Sci. 2003, 58, 846-850.

11. Corcoran, J.; Farkas, E.; Sobel, S. The Original Martial Arts Encyclopedia: Tradition, History, Pioneers; Pro-Action Publications: Los Angeles,CA, USA, 1993.

12. Alexandrov, A.; Frolov, A.A.; Massion, J. Biomechanical analysis of movement strategies in human forward trunk bending. I. Modeling. Biol. Cybern. 2001, 84, 425-434.

13. Fong, SS.; Ng, G.Y. Does taekwondo training improve physical fitness? Phys. Ther. Sport 2011, 12, 100-106.

14. Verhagen, A.P.; de Vet, H.C.; de Bie, R.A.; Kessels, A.G.; Boers, M.; Bouter, L.M.; Knipschild, P.G. The delphi list: A criteria list for quality assessment of randomized clinical trials for conducting systematic reviews developed by delphi consensus. J. Clin. Epidemiol. 1998, 51, 1235-1241.

15. Li, Y.; Devault, C.N.; van Oteghen, S. Effects of extended tai chi intervention on balance and selected motor functions of the elderly. Am. J. Chin. Med. 2007, 35, 383-391.

16. Pons van Dijk, G.; Lenssen, A.F.; Leffers, P.; Kingma, H.; Lodder, J. Taekwondo training improves balance in volunteers over forty. Front. Aging Neurosci. 2013, 5, 10. doi:10.3389/fnagi.2013.00010. 
17. Douris, P.; Chinan, A.; Gomez, M.; Aw, A.; Steffens, D.; Weiss, S. Fitness levels of middle aged martial art practicioners. Br. J. Sports Med. 2004, 38, 143-147.

18. Brudnak, M.A.; Dundero, D.; van Hecke, F.M. Are the "hard" martial arts, such as the korean martial art, taekwon-do, of benefit to senior citizens? Med. Hypotheses 2002, 59, 485-491.

19. Chateau-Degat, M.-L.; Papouin, G.; Saint-Val, P.; Lopez, A. Effect of adapted karate training on quality of life and body balance in 50-year-old men. Open Access J. Sports Med. 2010, 1, 143-150.

20. Jansen, P.; Dahmen-Zimmer, K. Effects of cognitive, motor, and karate training on cognitive functioning and emotional well-being of elderly people. Front. Psychol. 2012, 3, 40. doi:10.3389/fpsyg.2012.00040.

21. Leplege, A.; Ecosse, E.; Pouchot, J.; Coste, J.; Perneger, T. Le questionnaire MOS SF-36: Manuel de L'itilisateur et Guide de L'interpretation des Scores; Editions Estem: Paris, France, 2001.

22. Pons van Dijk, G.; Leffers, P.; Lodder, J. Feasibility, safety and subjective experience of a one-year WTF-Taekwondo training course for middle-aged volunteers: The Sekwondo study. Gazz. Med. Ital. Arch. Sci. Med. 2013, 172, 433-441.

23. Tsang, T.W.; Kohn, M.; Chow, C.M.; Singh, M.F. Health benefits of kung fu: A systematic review. J. Sports Sci. 2008, 26, 1249-1267.

(C) 2014 by the authors; licensee MDPI, Basel, Switzerland. This article is an open access article distributed under the terms and conditions of the Creative Commons Attribution license (http://creativecommons.org/licenses/by/3.0/). 